\title{
„Der Weg ist steiniger geworden“
}

\author{
Einem Zufall verdankt es Dr. Christian Honert (40), dass er als Partner in der Praxis seines Onkels \\ Dr. Wolfgang Honert in Asbach landete: Während einer Urlaubsvertretung gefiel es ihm, der ur- \\ sprünglich aus Langenfeld in Nordrhein-Westfalen kommt, so gut im Westerwald, dass er be- \\ schloss, sich dort niederzulassen.
}

„Die Patienten und die Mitarbeiter haben mich sehr herzlich aufgenommen, und ich empfand es als große Hilfe, dass da ein älterer Kollege, also mein Onkel, war, der mir über die Schulter schauen konnte. Schließlich sehen vier Augen mehr als zwei. Hinzu kam, dass mir das Leben auf dem Land mit dem hohen Freizeitwert sehr liegt."

Und so schwingt sich Honert am Feierabend und am Wochenende gern mal aufs Mountainbike, geht eine Runde laufen oder wirft den Grill an. Die Natur ist für den verheirateten Vater einer vierjährigen Tochter, wie er sagt, sehr wichtig.

Mittlerweile ist es zehn Jahre her, dass er sich - nach Examen 2003, Promotion 2004 und der Assistenzzeit - in Asbach niederließ. Die Niederlassung selbst ist für ihn ein eigentlich selbstverständlicher Schritt gewesen: Schon früh hat Honert das Bedürfnis, sich selbst verwirklichen zu wollen. Und dass er dabei nicht immer nur Vorgaben umsetzen, sondern auch aktiv mitgestalten möchte. Dem jungen Zahnarzt ist klar: „In der Niederlassung geht das am besten, da bin ich mein eigener Chef und kann mich dahingehend entwickeln, was am besten in die Praxis passt. Das ist besser als nicht realisierbare Konzepte umzusetzen, die von außen aufgedrückt werden."

An der Niederlassung schätzt er vor allem die Freiheit, selbst entscheiden zu können: Wann und wie er arbeitet, welche Patienten er hat, seine Fortbildungen nach Rücksprache mit seinem Onkel und Kompagnon zu planen und sich gegenseitig den Rücken frei zu halten.

\section{"Ganz so frei geht es in der Praxis nicht mehr zu“}

Doch zusehends mehr werde ihm als Zahnarzt von außen „übergestülpt“, findet Honert: „Vor allem seit der „Gesetzesflut“ wie dem Versorgungsstärkungsgesetz, dem E-Health-Gesetz und überdimensionierten Dokumentationspflichten merke ich: Ganz so frei geht es in der Zahnarztpraxis nun nicht mehr zu, da wird von außen stark Einfluss auf die Praxisbürokratie genommen. Und jede Stunde, die man mehr am Rechner sitzen muss, fehlt nachher am Patienten."

Der erhöhte Aufwand, etwa in Bezug auf das Qualitätsmanagement, zwinge die Zahnärzte, auch nach Ende der Sprechzeiten viel Bürokratisches zu erledigen. Honert prophezeit: „Je mehr man von außen vorgibt, desto mehr sind junge Kollegen von der Niederlassung abgeschreckt. Junge Zahnärzte wollen nicht an 24 Stunden sieben Tage die Woche arbeiten, denen ist die Work-Life-Balance sehr wichtig. Diese massive überbordende Bürokratie erschwert es, Nachwuchskräfte zu finden, die langfristig dabei sein möchten und neben der Arbeit auch mit ihrem Familienleben glücklich sind. Das alles lässt dann auch umso weniger Zeit, um sich standespolitisch zu engagieren."

Mit seinem Onkel spricht er über so manche Veränderung, auch um zu erfahren, wie der Ältere das damals gehandhabt hat. Honert betont: „Veränderungen sind nicht immer negativ zu sehen." Gerade die Anforderungen im Bereich Hygiene seien sinnvoll, aber bei 30 Patienten am Tag litten letztlich alle unter den staatlichen Maßgaben.

\section{„Warum dieser Wahnsinn an Kontrolle?"}

Sein Vorschlag: Mancher bürokratische Ablauf sollte einfach besser an die einzelne Praxis angepasst werden. „Wir organisieren unsere Fortbildungen innerhalb der Kammern und die Förderung der Mitarbeiter ja selbst, da frage ich mich: Warum dieser Wahnsinn an Überwachung und Kontrolle, an bürokratischen Hürden?"

Ob er seinen Onkel um die früher größere Selbstbestimmtheit beneidet? Honert findet, dass jede Zeit ihre Herausforderungen habe, früher habe es eben andere Herausforderungen gegeben.

Heute seien jedenfalls Netzwerke wie der Freie Verband und young dentists, aber auch die Kammern und die KZVen für den schnellen Informationsaustausch wichtig. Weichenstellungen, die nicht nur den Einzelnen angehen, sondern in die Zukunft weisen, seien gefragt. „Es geht um die jungen Zahnärztinnen und Zahnärzte, die den Job die nächsten 40 Jahre machen müssen. Den jungen Leuten muss auch klar sein, dass für jeden, der ins Angestelltenverhältnis möchte, auch ein Chef da sein muss, der einstellen kann.“

Trotz allem: Der Beruf als solcher und die Arbeit an den Patienten machen Honert nach wie vor viel Spaß, sagt er. Auch wenn der Weg steiniger geworden ist: Er würde ihn nochmal gehen, auf jeden Fall.

Maike Raack 